Anal. Caled for $\mathrm{C}_{20} \mathrm{H}_{16} \mathrm{O}_{4}: \mathrm{C}, 75.0 ; \mathrm{H}, 5.0$. Found: C, 75.0; $\mathrm{H}$ 5.0

3-Deoxysericetin (16) and 3-Deoxyisosericetin (15). To a solution of $2(500 \mathrm{mg})$ in dry benzene $(40 \mathrm{ml})$ was added DDQ (300 $\mathrm{mg}$ ) and the whole solution refluxed for $1 \mathrm{hr}$. It was filtered while hot, benzene distilled off, and the residue subjected to column chromatography. Elution with benzene-light petroleum (2:8) gave a solid which again proved to be a mixture. Fractional crystallization with light petroleum (mother liquor A) yielded the sparingly soluble solid which on recrystallization from ethyl acetatelight petroleum mixture afforded 5-hydroxy-6-prenyl- $6^{\prime \prime}, 6^{\prime \prime}$-dimethylpyrano[ $\left.2^{\prime \prime}, 3^{\prime \prime}: 7,8\right]$ flavone [3-deoxyisosericetin (15)] (120 $\mathrm{mg}$ ): $\mathrm{mp} 156^{\circ} ; R_{\mathrm{f}} 0.78$ (solvent $\mathrm{A}$ ); light green ferric reaction; $\mathrm{nmr}$ $\delta 1.50\left[\mathrm{~s}, 6,\left(\mathrm{CH}_{3}\right)_{2} \mathrm{C}<\right.$ ], $1.70,1.83$ [2 broad s, 6, $\left(\mathrm{CH}_{3}\right)_{2} \mathrm{C}=$ ], 3.41 $\left(d, 2, J=7 \mathrm{~Hz}, \mathrm{ArCH}_{2}\right), 5.33(\mathrm{~m}, 1,-\mathrm{CH}=), 5.676 .88(2 \mathrm{~d}, 2, J$ $=10 \mathrm{~Hz}$, two olefinic $\mathrm{H}$ of pyran ring), $6.70(\mathrm{~s}, 1 \mathrm{H}$ in position 3$)$, $7.59\left(\mathrm{~m}, 3 \mathrm{H}\right.$ in positions $3^{\prime}, 4^{\prime}$, and $\left.5^{\prime}\right)$ and $7.93(\mathrm{~m}, 2 \mathrm{H}$ in positions $2^{\prime}$ and $\left.6^{\prime}\right)$; mass spectrum $(70 \mathrm{eV}) \mathrm{m} / \mathrm{e}$ (rel intensity) 388 (85), 373 (100), $345(57), 332(63), 317(11), 215(17), 165(11), 105$ (11), 77 (10)

5.9.

The mother liquor $A$ yielded a solid which after crystallization twice from methanol yielded 5-hydroxy-8-prenyl- $6^{\prime \prime}, 6^{\prime \prime}$-dimethylpyrano[2",3":7,6]flavone [3-deoxysericetin (16)] $(80 \mathrm{mg})$ as pale yellow needles: $\mathrm{mp} 166^{\circ} ; R_{\mathrm{f}} 0.74$ (solvent $\mathrm{A}$ ); intense green ferric reaction; $\mathrm{nmr} \delta 1.50\left[\mathrm{~s}, 6,\left(\mathrm{CH}_{3}\right)_{2} \mathrm{C}<\right], 1.72,1.79[2 \mathrm{~d}, 6, J=2 \mathrm{~Hz}$, $\left.\left(\mathrm{CH}_{3}\right)_{2} \mathrm{C}=\right], 3.56\left(\mathrm{~d}, 2, J=7 \mathrm{~Hz}, \mathrm{ArCH}_{2}\right), 5.26(\mathrm{~m}, 1,-\mathrm{CH}=)$, $5.66,6.81(2 \mathrm{~d}, 2, J=10 \mathrm{~Hz}$, two olefinic $\mathrm{H}$ of pyran ring), 6.71 (s, $1 \mathrm{H}$ in position 3$), 7.59\left(\mathrm{~m}, 3 \mathrm{H}\right.$ in positions $3^{\prime}, 4^{\prime}$, and $\left.5^{\prime}\right)$, and $7.96\left(\mathrm{~m}, 2 \mathrm{H}\right.$ in positions $2^{\prime}$ and $\left.6^{\prime}\right)$; mass spectrum $(70 \mathrm{eV}) \mathrm{m} / \mathrm{e}$ (rel intensity) $388(82), 373(100), 345(68), 333(73), 215(28), 165$ (14), $105(27), 85(36), 77(22), 71(55), 55(46)$ 5.9

Acknowledgment. One of us (B. N. S.) thanks UGC, India, for a fellowship.

Registry No.-1, 480-40-0; 2, 50678-89-2; 2 diacetate, 50678 90-5; 3, 50678-91-6; 3 diacetate, 50678-92-7; 4, 50678-93-8; $\mathbf{5}$, $50678-94-9 ; 6,50678-95-0 ; 7,50678-96-1 ; 8,50830-97-2 ; 9,50678$. $97-2 ; 10,34187-26-3 ; 11,34125-75-2 ; 11$ diacetate, 50678-98-3; 12 $50678-99-4 ; 13,50679-00-0 ; 14,34187-25-2 ; 15,50679-01-1 ; 16$,
50679-02-2; prenyl bromide, 870-63-3; 2-hydroxy-2-methyl-3-butene, $115-18-4$

\section{References and Notes}

(1) Correspondence should be addressed to Department of Chemistry Himachal University, The Manse Building, Simla-1,71,001, India.

2) K. Venkataraman, Phytochem., 11, 157 (1972)

(3) P. V. Radha Krishnan, A. V. Rama Rao, and K. Venkataraman, Tetrahedron Lett., 663 (1965)

(4) P. C. Parthasarthy, P. V. Radha Krishnan, S. S. Rathi, and K. Venk ataraman. Indian J. Chem., 7, 101 (1969), and earlier papers in this series.

(5) K. G. Dave, R. Mani, and K. Venkataraman, J. Sci. Ind. Res., Sect. $B, 20,112$ (1961)

(6) K. G. Dave, S. A. Telang, and K. Venkataraman, Tetrahedron Lett, 9 (1962)

(7) A. V. Rama Rao, M. Vardan, and K. Venkataraman, Indian J. Chem., 9, 7 (1971)

(8) A. V. Rama Rao, S. S. Rathi, and K. Venkataraman, Indian J Chem., 10, 905, 989 (1972).

(9) V. H. Deshpande, P. C. Parthasarthy, and K. Venkataraman, Tetra hedron Lett., 1715 (1968)

(10) M. M. Pashchenko, G. P. Pivnenko, and V. I. Litvinenko, Formatsevt, Zh. Kiev., 21 (1), 44 (1966)

(11) M. M. Pashchenko and G. P. Pivnenko, Formatsevt, Zh. Kiev, 21 (5), 47 (1966)

(12) K. N. N. Ayengar, B. Y. Rama Sastry, and S. Rangaswami, Indian J. Chem., 11, 85 (1973)

(13) A. C. Jain, S. K. Mathur, and T. R. Seshadri, J. Sci. Ind. Res. Sect. $B, 21,214(1962)$.

(14) J. Hlubucek, E. Ritchie, and W. C. Taylor, Aust. J. Chem., 24, 2348 (1971).

(15) B. F. Burrows, W. D. Ollis, and L. M. Jackman, Proc. Chem. Soc. $177(1960)$

(16) A. V. Rama Rao, M. Varadan, and K. Venkataraman Indian Chem., 9, 7 (1971)

(17) All melting points were taken on Buchi melting point apparatus and are uncorrected. Tlc was carrled out on plates coated with silica gel supplied by NCL, Poona. Spraying reagent was generally $10 \%$ aqueous sulfuric acid, but $10 \%$ alcoholic ferric chloride was also used for such compounds which gave positive ferric reaction. TIc was carried out using one of the following solvent systems: (A) benzene, (B) benzene-ethyl acetate $(9: 1),(C)$ benzene-ethyl acetate $(75: 25)$, (D) benzene-ethyl acetate (1:1) Column chromatography was carried out using silica gel supplied by NCL, Poona. Nuclear magnetic resonance spectra were determined in $\mathrm{CDCl}_{3}$ using clear magnetic resonance spectra were determined in $\mathrm{CDCl}_{3}$ using
$60 \mathrm{MHz}$ spectrophotometer. Chemical shitts are expressed in parts per million (ppm) downfield from tetramethylsilane as internal standard. Mass spectra were determined on samples introduced through the heated inlet system using MS 72 spectrometer, $70 \mathrm{eV}$ ionizing voltage, $900 \times 10$ trap current, and $2.0 \mathrm{kV}$ accelerating voltage.

\title{
1,8 Interactions in Naphthalene Derivatives. An X-Ray Structure Determination and Nuclear Magnetic Resonance Studies of 1,8-Di(bromomethyl)naphthalene ${ }^{1}$
}

\author{
J.-B. Robert, ${ }^{2}$ J. S. Sherfinski, Richard E. Marsh, and John D. Roberts* \\ Contribution No. 4790 from the Gates and Crellin Laboratories of Chemistry, California Institute of Technology, \\ Pasadena, California 91109
}

Received November 13, 1973

\begin{abstract}
The conformation of 1,8-di(bromomethyl)naphthalene has been determined in the crystalline state and it has been found that the molecule has essentially twofold symmetry about the C-9-C-10 bond with the bromines located above and below the plane of the ring. The carbon-bromine bonds are inclined toward one another about $10^{\circ}$ from planes perpendicular to the naphthalene ring which contain the C-1-C-11 and C-8-C12 bonds. This conformation has formally nonbonded $\mathrm{H}$...Br distances of $2.85 \AA$ which are substantially less than the sum of the van der Waals radii and could well indicate some degree of electrostatic binding. The strain in the molecule is largely relieved both by in-plane and out-of-plane bending of the C-1-C-11 and the C-8-C-12 bonds as well as some skeletal distortion of the ring. Low-temperature proton nmr studies of 1,8-di(bromomethyl)naphthalene and some related compounds showed no evidence of barriers to rotation about the $\mathrm{C}-1-\mathrm{C}-11$ and $\mathrm{C}-8-\mathrm{C}-12$ bonds large enough to be detectable.
\end{abstract}

Alkyl or aryl substituents at the 1,8 positions (the peri positions) of naphthalene are in close proximity to one another and provide many interesting opportunities for study of conformations and barriers to rotation about the extracyclic bonds, C-1-C-11 and C-8-C-12.3,4 Relatively few other simple molecules have the special feature of having the substituents close to one another and attached to a relatively rigid framework by essentially parallel bonds. Because of the importance of knowing just what conformations are, in fact, favored for molecules of this type, we have determined the structure of 1,8-di(bromomethyl)naphthalene (1) by X-ray diffraction. On the as- 


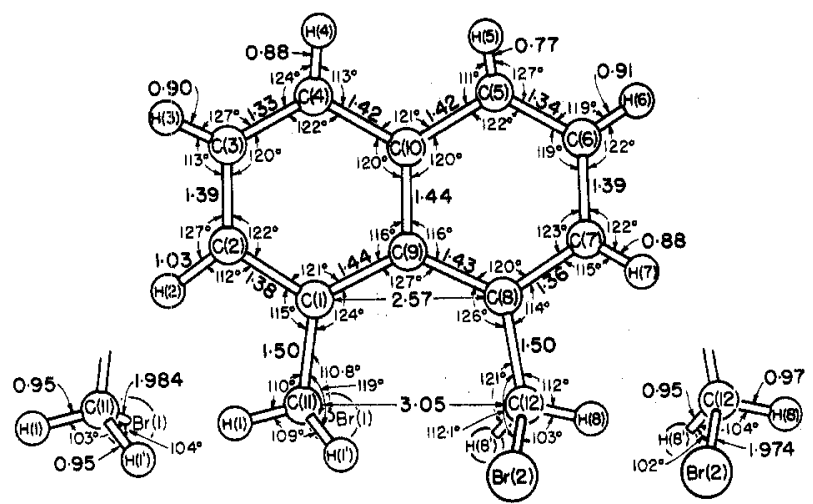

Figure 1. Bond angles and bond distances found for 1 in the crystal. Estimated standard deviations in the bond distances are about $0.006 \AA$ for $\mathrm{C}-\mathrm{Br}, 0.01 \AA$ for $\mathrm{C}-\mathrm{C}$, and $0.06 \AA$ for $\mathrm{C}-\mathrm{H}$.

sumption that the conformation observed for the solid state might also be important in solution, we have investigated the proton $\mathrm{nmr}$ spectra of 1 and of several related compounds $(2-4)$ at low temperatures.

$$
\begin{aligned}
& 1, \mathrm{X}=\mathrm{Br} \\
& 2, \mathrm{X}=\mathrm{H} \\
& 3, \mathrm{X}=\mathrm{Cl} \\
& 4, \mathrm{X}=\mathrm{OH}
\end{aligned}
$$

Most of the 1,8-disubstituted naphthalenes bearing substituents at the 1,8 positions whose structures have been investigated by X-ray diffraction have been halogen derivatives. These substances have no complications of extracyclic conformations but do show substantial nonplanarity, both of the halogens with respect to the rings and of the naphthalene rings themselves. ${ }^{5}$ Relief of steric strain is normally most easily achieved by bond bending, but for 1,8-disubstituted naphthalenes there is a buttressing effect exerted by the 2,7 hydrogens which tends to favor out-of-plane distortions. This type of interaction for dihalonaphthalenes reaches an extreme with 1,8-diiodonaphthalene. ${ }^{6}$

The crystallographic investigations of substances where conformational properties should be important include 3bromo-1,8-dimethyl-7 and octamethylnaphthalenes, ${ }^{8}$ but in these two studies the methyl hydrogens were not located; 1,8-dinitronaphthalene, ${ }^{9}$ where the planes of the nitro groups are twisted about $43^{\circ}$ from the plane of the ring; 1,4,5,8-tetranitronaphthalene $\mathrm{e}^{10}$ with similar conformations of the nitro groups; 1,8-diphenylnaphthalene, ${ }^{4 a}$ where the phenyl rings are face-to-face but substantially splayed outward and inclined to approximately $45^{\circ}$ from the plane of the naphthalene ring; 1,4,5,8-tetraphenylnaphthalene, ${ }^{11}$ which is similarly disposed; the conjugate acid of 1,8 -bis(dimethylamino) naphthalene, ${ }^{12}$ which has the added proton in the plane of the ring shared between the two nitrogen lone pairs; the methyl groups are above and below the plane; and 1,8-bis(dimethylamino)naphthalene, ${ }^{13}$ the only case really comparable to the present one in that it involves saturated substituents. 1,8-Bis(dimethylamino)naphthalene assumes what appears to be a compromise conformation (5), with the methyl groups not in the most favorable location to avoid the hydrogens on $\mathrm{C}-2$ and $\mathrm{C}-7$, with the unshared pairs not face-to-face, and possibly with some degree of lone-pair delocalization in the ring (which, of course, would be particularly favored with the methyl groups in the plane of the ring)<smiles>CC(C)c1ccc2c(N(C)C)cccc2c1</smiles>

5

Some of the more symmetrical, possible conformations of 1 are 6-8, which represent end-on views at $\mathrm{C}-11$ and $\mathrm{C}-12$ and are chosen to avoid close proximity of bromines with the respective opposite carbons $\mathrm{C}-11$ and $\mathrm{C}-12$, or other obvious steric conflicts between substituents on these atoms. Of these, 6 would be expected to be the least favorable because of the eclipsing of the hydrogens and the interactions of the bromines with the hydrogens at C-2 and C-7. Arrangements 7 and 8 relieve these interactions at the cost of creating new nonbonded hydrogen-hydrogen (and, for 8, hydrogen-bromine) interactions. Clearly, the mode by which the molecule resolves these conflicts is of substantial interest.<smiles>BrCCBr</smiles><smiles>BrC=CBr</smiles><smiles>BrC=CBr</smiles>

8

\section{Experimental Section}

1,8-Di(bromomethyl)naphthalene (1) was prepared as described ${ }^{14}$ and recrystallized from ether. Preliminary Weissenberg and precession photographs indicated the monoclinic space group $C 2 / c$ (systematic absences: $h k l$ for $(h+k)$ odd, $h 0 l$ for $l$ odd). Unit-cell dimensions were derived from a least-squares fit to 20 values for 15 medium- to high-angle reflections centered on a diffractometer; they are $a=23.500 \pm 0.004 \AA, b=7.662 \pm 0.002 \AA$, $c=12.543 \pm 0.006 \AA, \beta=95.73 \pm 0.02^{\circ} .15$ The density calculated for eight molecules in the unit cell is $1.856 \mathrm{~g} \mathrm{~cm}^{-3}$, in satisfactory agreement with the value $1.850 \pm 0.002 \mathrm{~g} \mathrm{~cm}^{-3}$ measured by flotation.

The crystal used for collection of intensity data was an approximate cube, $0.2 \mathrm{~mm}$ on an edge, mounted along the $c$ axis. Intensities were measured using a Datex-automated General Electric three-circle diffractometer equipped with a copper-target X-ray tube, $\mathrm{Ni}$ filter, scintillation counter, and pulse-height analyzer.

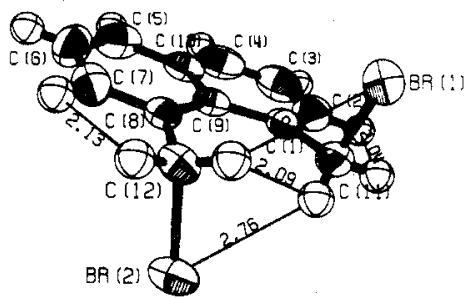

Figure 2. Stereoview of 1,8-di(bromomethyl)naphthalene (1) as it exists in the crystal. 
Table I

Atomic Coordinates As Determined by X-Ray Diffraction ${ }^{\alpha}$

\begin{tabular}{|c|c|c|c|}
\hline & $x$ & $y$ & $z$ \\
\hline $\mathrm{Br}(1)$ & $0.15221(3)$ & $-0.29088(8)$ & $0.00417(5)$ \\
\hline $\mathrm{Br}(2)$ & $0.09420(3)$ & $0.16626(9)$ & $-0.24065(5)$ \\
\hline C (1) & $0.1777(2)$ & $0.0748(7)$ & $0.0346(4)$ \\
\hline $\mathrm{C}(2)$ & $0.2267(3)$ & $0.1128(10)$ & $0.1000(5)$ \\
\hline$C(3)$ & $0.2270(4)$ & $0.2348(11)$ & $0.1820(6)$ \\
\hline C (4) & $0.1785(4)$ & $0.3152(10)$ & $0.2002(5)$ \\
\hline $\mathrm{C}(5)$ & $0.0752(4)$ & $0.3690(8)$ & 0.1591 (5) \\
\hline $\mathrm{C}(6)$ & $0.0258(3)$ & $0.3454(9)$ & $0.0981(6)$ \\
\hline$C(7)$ & $0.0251(3)$ & $0.2396(8)$ & $0.0079(5)$ \\
\hline$C(8)$ & $0.0719(2)$ & $0.1498(7)$ & $-0.0182(4)$ \\
\hline$C(9)$ & $0.1251(2)$ & $0.1657(6)$ & $0.0470(4)$ \\
\hline$C(10)$ & $0.1261(3)$ & $0.2834(7)$ & 0.1365 (4) \\
\hline C (11) & $0.1838(3)$ & $-0.0682(9)$ & $-0.0452(5)$ \\
\hline C (12) & $0.0623(3)$ & $0.0475(8)$ & $-0.1202(4)$ \\
\hline $\mathrm{H}(1)$ & $0.223(2)$ & $-0.095(7)$ & $-0.048(4)$ \\
\hline $\mathrm{H}\left(1^{\prime}\right)$ & $0.166(2)$ & $-0.055(7)$ & $-0.116(4)$ \\
\hline $\mathrm{H}(2)$ & $0.261(2)$ & $0.039(7)$ & $0.081(4)$ \\
\hline $\mathbf{H}(3)$ & $0.262(2)$ & $0.254(7)$ & $0.216(4)$ \\
\hline $\mathrm{H}(4)$ & $0.176(2)$ & $0.396(7)$ & 0.250 \\
\hline $\mathrm{H}(5)$ & $0.081(2)$ & $0.431(7)$ & $0.208(4)$ \\
\hline $\mathrm{H}(6)$ & $-0.006(2)$ & $0.404(7)$ & $0.114(4)$ \\
\hline $\mathbf{H}(7)$ & $-0.006(2)$ & $0.227(7)$ & $-0.037(4)$ \\
\hline $\mathrm{H}(8)$ & $0.022(2)$ & $0.038(7)$ & $-0.145(4)$ \\
\hline $\mathrm{H}\left(8^{\prime}\right)$ & $0.077(2)$ & $-0.067(7)$ & $-0.125(4)$ \\
\hline
\end{tabular}

${ }^{a}$ Values in parentheses are standard deviations in the last digit.

All reflections with $2 \theta<120^{\circ}$ were recorded using a $\theta-2 \theta$ scan mode at a scan rate of $1^{\circ}$ (in $2 \theta$ ) $/$ min; the scan width varied from $2.0^{\circ}$ at $2 \theta=0^{\circ}$ to $2.9^{\circ}$ at $2 \theta=120^{\circ}$. A 20 -sec background count was recorded at each scan extremum. Three check reflections (10 $2,2 ; 10,0,6 ; 0,2,4)$ were recorded periodically; they showed steady but somewhat unequal drops in intensity, averaging about $10 \%$ over the 5 -day period. The recorded intensities were corrected for this average decay, and for Lorentz and polarization effects; no absorption corrections were applied $(\mu r \approx 1.0)$. Assigned variances $\sigma^{2}\left(F_{0}^{2}\right)$ were based on counting statistics plus the term $(0.02 S)^{2}$, where $S$ is the scan count. Of the 1675 independent reflections that were recorded, 1551 had net intensities greater than zero.

The structure was derived by standard heavy-atom techniques beginning with a three-dimensional Patterson map. ${ }^{16}$ Two cycles of least-squares refinement of the heavy-atom coordinates $(\mathrm{C}$ and $\mathrm{Br}$ ) gave an $R$ value of 0.17 . During the remaining eight leastsquares cycles, additional parameters were added until they totaled 158: coordinates and anisotropic temperature factors for the 14 heavy atoms, coordinates for the 10 hydrogen atoms (which were initially assigned on geometric grounds), a scale factor, and a secondary-extinction parameter. ${ }^{17}$ The hydrogen atoms were assigned fixed, isotropic temperature factors with $B=5.0 \AA^{2}$. During the final refinement cycle, the largest shift in a heavyatom parameter was $0.5 \sigma$ and, in a hydrogen-atom coordinate,

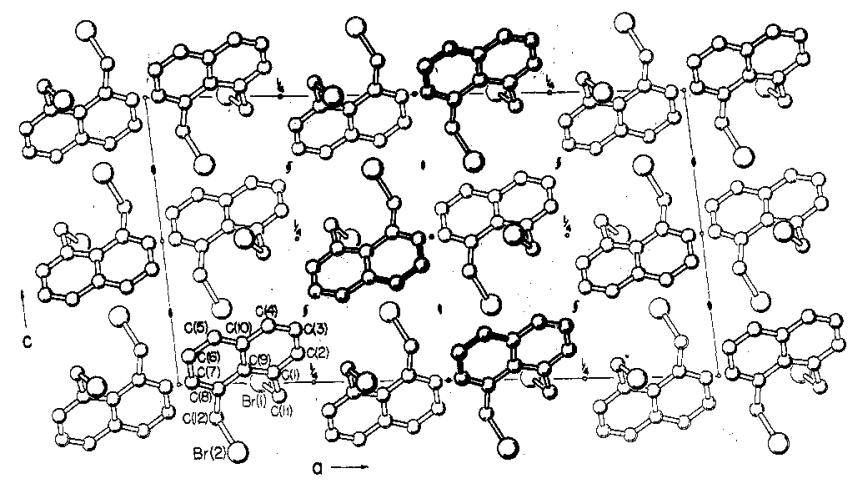

Figure 3. Arrangement of molecules of 1 in the crystal.

$0.9 \sigma$. The goodness-of-fit, $\left[\Sigma w\left(F_{0}{ }^{2}-F_{c}{ }^{2}\right)^{2} /(N-P)\right]^{1 / 2}$ for $N=$ 1675 reflections and $P=158$ parameters, was 1.36 ; the $R$ index, $\Sigma|| F_{\mathrm{o}}|-| F_{\mathrm{c}}|| / \Sigma\left|F_{\mathrm{o}}\right|$, was 0.056 for the 1551 reflections with net intensities greater than zero.

\section{Results and Discussion}

The final atomic coordinates are, given in Table I and the anisotropic temperature parameters in Table II. Bond distances and angles are shown in Figure 1, a stereoptic view of the molecule in Figure 2, and the arrangement of the molecules in Figure 3.

Bond distances in the naphthalene ring are in excellent agreement with values found in 1,8-bis(dimethylamino)naphthalene, the only other 1,8-disubstituted naphthalene derivative to have been studied with comparable accuracy. Once again we note that the four ring $\mathrm{C}-\mathrm{C}$ bonds involving $\mathrm{C}-1$ and $\mathrm{C}-8$ are appreciably longer-by an average of $0.025 \AA$ in the present case-than the corresponding bonds involving $\mathrm{C}-4$ and $\mathrm{C}-5$. In the case of 1,8-bis(dimethylamino)naphthalene ${ }^{13}$ the effect was somewhat larger, $0.035 \AA$, and was attributed in part to the electronwithdrawing ability of the substituent nitrogen atoms, and in part to overcrowding of the peri groups. In the present case, the substituent $-\mathrm{CH}_{2} \mathrm{Br}$ groups should have little electronic influence on the ring bonds, so that the distortion must be blamed almost entirely on overcrowding. A comparison of bond distances with those found for naphthalene ${ }^{18}$ and perdeuterionaphthalene ${ }^{19}$ suggests that this overcrowding leads to a redistribution of bonding electrons within the naphthalene nucleus, the bonds involving $\mathrm{C}-4$ and $\mathrm{C}-5$ being shortened by about the same amount that those involving $\mathrm{C}-1$ and $\mathrm{C}-8$ are lengthened.

Overcrowding between the peri $-\mathrm{CH}_{2} \mathrm{Br}$ groups is relieved in two additional ways: in-plane bending of the $\mathrm{C}$ 1-C-11 and C-8-C-12 bonds, and out-of-plane distortions involving the entire molecule. Deviations of the individual

Table II

Anisotropic Temperature Parameters

\begin{tabular}{|c|c|c|c|c|c|c|}
\hline & $B_{11}$ & $B_{22}$ & $B_{38}$ & $B_{12}$ & $B_{13}$ & $B_{23}$ \\
\hline $\mathrm{Br}$ (1) & $6.06(4)$ & $4.59(3)$ & $5.27(4)$ & $1.41(3)$ & $1.22(3)$ & $0.72(3)$ \\
\hline $\operatorname{Br}(2)$ & $6.08(4)$ & $5.77(4)$ & $3.40(3)$ & $-0.16(3)$ & $0.02(2)$ & 1.24 (3) \\
\hline C (1) & $3.7(3)$ & $4.1(3)$ & $3.4(2)$ & $0.0(2)$ & $0.3(2)$ & $1.1(2)$ \\
\hline C (2) & $4.2(3)$ & $6.9(4)$ & $4.5(3)$ & $0.2(3)$ & $-0.2(3)$ & $0.9(3)$ \\
\hline C (3) & $5.5(4)$ & $7.3(5)$ & $5.0(4)$ & $-1.6(4)$ & $-1.4(3)$ & $1.4(3)$ \\
\hline C (4) & $8.7(5)$ & $5.2(4)$ & $3.8(3)$ & $-2.0(4)$ & $0.0(3)$ & $0.0(3)$ \\
\hline C (5) & $8.9(5)$ & $3.4(3)$ & $4.6(3)$ & $-0.2(3)$ & $2.3(4)$ & $-0.9(2)$ \\
\hline$C(6)$ & $5.6(4)$ & $4.7(3)$ & $7.3(4)$ & $1.1(3)$ & $2.4(4)$ & $0.4(3)$ \\
\hline C (7) & $4.7(3)$ & $4.7(3)$ & $4.9(4)$ & $0.6(3)$ & $0.2(3)$ & $0.3(3)$ \\
\hline C (8) & $4.2(3)$ & $3.1(2)$ & $3.3(2)$ & $0.1(2)$ & $0.7(2)$ & $0.8(2)$ \\
\hline C (9) & $4.2(3)$ & $3.1(2)$ & $2.8(2)$ & $-0.5(2)$ & $0.5(2)$ & $0.7(2)$ \\
\hline C (10) & $5.8(3)$ & $3.2(3)$ & $3.1(3)$ & $-0.9(3)$ & $0.4(2)$ & $0.4(2)$ \\
\hline C (11) & $4.0(3)$ & $5.8(3)$ & $3.6(3)$ & $1.1(3)$ & $0.7(2)$ & $1.1(3)$ \\
\hline $\mathrm{C}(12)$ & $4.1(3)$ & $3.9(3)$ & $3.5(3)$ & $-0.1(2)$ & $-0.3(2)$ & $0.5(2)$ \\
\hline
\end{tabular}

${ }^{a}$ Values in parentheses are standard deviations in the last digit. The temperature factors have the general form exp $-1 / 4$ $\left(B_{11} h^{2} a^{* 2} \ldots+2 B_{23} k l b{ }^{*} c^{*}\right)$. 
Table III

Deviations from the Least-Squares Plane of the Naphthalene Ring ${ }^{a}$

\begin{tabular}{lrlr}
\hline Atom & Deviation, $\AA$ & Atom & Deviation, $\AA$ \\
\hline C $(1)$ & -0.068 & $\mathrm{C}(8)$ & 0.051 \\
$\mathrm{C}(2)$ & -0.020 & $\mathrm{C}(7)$ & 0.045 \\
$\mathrm{C}(3)$ & 0.047 & $\mathrm{C}(6)$ & -0.041 \\
$\mathrm{C}(4)$ & 0.037 & $\mathrm{C}(5)$ & -0.041 \\
$\mathrm{C}(9)$ & 0.000 & $\mathrm{C}(10)$ & -0.010 \\
$\mathrm{C}(11)$ & -0.229 & $\mathrm{C}(12)$ & 0.188 \\
$\mathrm{Br}(1)$ & -2.110 & $\mathrm{Br}(2)$ & 2.024
\end{tabular}

a The plane was passed through atoms C-1-C-10, all weighted equally. The direction cosines of the plane relative to $a, b$, and $c$ are $0.2911,0.7511$, and -0.6186 , and the origin-to-plane distance is $1.445 \AA$.

Table IV

Ring-Proton Coupling Constants and Chemical-Shift Differences for 1,8-Di (bromomethyl)naphthalene $(1)$, 1,8-Dimethylnaphthalene $(2)$,

1,8-Di (chloromethyl)naphthalene $(3)$, and 1,8-Di(hydroxymethyl) naphthalene (4)

\begin{tabular}{clccccc}
\hline Compd & Solvent & $J_{28,}, \mathrm{~Hz}$ & $J_{24}, \mathrm{~Hz}$ & $J_{34}, \mathrm{~Hz}$ & $\delta_{48,}, \mathrm{ppm}$ & $\delta_{42,}, \mathrm{ppm}$ \\
\hline $\mathbf{1}$ & $\mathrm{CCl}_{4}$ & 7.5 & $\mathbf{1 . 6}$ & 8.5 & 0.28 & 0.43 \\
$\mathbf{2}$ & $\mathrm{CCl}_{4}$ & 7.0 & 1.8 & 7.4 & 0.38 & 0.42 \\
$\mathbf{3}$ & $\mathrm{CCl}_{4}$ & 7.5 & 1.4 & 8.9 & 0.30 & 0.44 \\
$\mathbf{4}$ & $\mathrm{DMSO}^{a}$ & 7.5 & 1.5 & $\mathbf{8 . 6}$ & 0.23 & 0.42
\end{tabular}

a Dimethyl sulfoxide.

atoms from the mean plane of the naphthalene ring are given in Table III. These deviations are smaller than in the dimethylamino compound, ${ }^{13}$ while the in-plane splaying of the $\mathrm{C}-\mathrm{CH}_{2} \mathrm{Br}$ bonds is larger; presumably the double-bond character in the $\mathrm{C}-1-\mathrm{N}$ and $\mathrm{C}-8-\mathrm{N}$ bonds of the dimethylamino compound makes bond bending a less attractive mechanism for relieving strain than in the present case.

The puckering of the naphthalene system is accomplished primarily by a twist about the central C-9-C-10 bond by about $4^{\circ}$ in the present compound and $9^{\circ}$ in the dimethylamino compound. This twist apparently results in a redistribution of electrons in the ring system, for in both compounds (as well as in other peri compounds ${ }^{7-13}$ the C-9-C-10 bond is significantly longer than in naphthalene and perdeuterionaphthalene while the $\mathrm{C}-2-\mathrm{C}-3$ and C-6-C-7 bonds are marginally shorter.

The $\mathrm{C}-1-\mathrm{C}-11$ and $\mathrm{C}-8-\mathrm{C}-12$ bonds are sufficiently nonparallel as to result in a C-11...C-12 distance of $3.05 \AA$ compared to $2.57 \AA$ for $\mathrm{C}-1 \ldots \mathrm{C}-8$. This $\mathrm{C}-11 \ldots \mathrm{C}-12$ distance is substantially larger than the corresponding distance in 3-bromo-1,8-dimethylnaphthalene, $2.92 \AA^{7}$ The conformations about the $\mathrm{C}-\mathrm{CH}_{2} \mathrm{Br}$ bonds are such that the bromine atoms are directed to opposite sides of the molecular plane: the torsion angles $\mathrm{C}-2-\mathrm{C}-1-\mathrm{C}-11-\mathrm{Br}$ 1 and $\mathrm{C}-7-\mathrm{C}-8-\mathrm{C}-12-\mathrm{Br}-2$ are 101.1 and $101.8^{\circ}$. A number of the nonbonded distances (Figure 2) are less than the sums of the van der Waals radii as given by Pauling ${ }^{20}$ or Bondi. $^{21}$ The most uncomfortable interactions appear to be the $\mathrm{Br}-1 \ldots \mathrm{H}-8^{\prime}(2.85 \AA)$ and $\mathrm{Br}-2 \ldots \mathrm{H}-1^{\prime}(2.76 \AA)$ contacts; however, it is possible that these interactions include electrostatic attraction effects of the type postulated to account for the unusual stability of axial halogens on cyclohexane rings in the presence of polar groups. ${ }^{22}$

Nmr Studies. The arrangement and general tightness of the bromomethyl groups of 1 as shown in Figure 2 suggest that the hydrogens on the methylene groups should be nonequivalent and that there might be a significant barrier to rotation, a process which would, of course, make the methylene hydrogens on the average equivalent. For this reason, some variable-temperature nmr studies were made of 1 and some related compounds, 2,3 , and 4 . At room temperature, the proton interactions on the ring carbons of 1-4 were analyzed ${ }^{23}$ as independent $A B C$ spin systems on the assumption that the couplings between the hydrogens on opposite sides of the molecule were small, as they are in other naphthalene derivatives. ${ }^{24}$ The results of these analyses are shown in Table IV and they accord generally with the work of others. ${ }^{24,25}$

For compounds 1-4, the methylene proton signals were single sharp lines at room temperature in carbon tetrachloride, while with 4 in dimethyl sulfoxide, hydroxyl exchange was slowed sufficiently so that the methylene signal was split into a doublet corresponding to a $J_{\mathrm{HCOH}}$ coupling of $5.3 \mathrm{~Hz}$.

The singlets observed for the methylene protons at room temperature remained unchanged for 1 in vinyl chloride down to $-130^{\circ}$, for 2 in the same solvent to $-140^{\circ}$, for 3 in dimethyl ether to $-130^{\circ}$, and for 4 in carbon disulfide to $-40^{\circ}$. Although these results are perhaps not too surprising in view of what has been reported recently, $4 c$ at the time the experiments were carried out, we considered some possible explanations of the results which did not require that the barrier to rotation be small, especially for 1. Briefly, these were (1) that the conformation of 1 in the crystal is dictated not by intramolecular but rather by intermolecular forces so that the stable conformation in solution is, in fact, 6; and (2) that the methylene protons might coincidentally have the same shifts even for 8 . The arguments against the first proposition are that the crystal structure shows no unusual intermolecular interactions which would favor 8 over 6 , although this argument is weakened by not having crystals of 6 and knowing what their structure would be like, and also that 6 would be expected to have very substantial $\mathrm{H}-2 \cdots \mathrm{Br}-1$ and $\mathrm{H}$ $7 \ldots \mathrm{Br}-2$ interactions. The possibility that the chemical shifts would be coincident seems highly unlikely on the basis of a crude ring-current effect calculation which suggests that there should be perhaps $0.15 \mathrm{ppm}$ difference in shift between them. There will also be a substantial influence produced by the bromines on the immediately adjacent hydrogens, of $\mathrm{Br}-1$ on $\mathrm{H}-8^{\prime}$ and of $\mathrm{Br}-2$ on $\mathrm{H}-1^{\prime}$. Qualitatively, one would expect that these influences on the close protons would be in the same direction (downfield) as the ring-current effect. For this reason, it seems quite unlikely that accidentally coincident chemical shifts are involved, and we conclude that rapid rotation is the correct explanation for the variable-temperature spectra. For 1-3, the free energies of activation for rotation are probably less than $8 \mathrm{kcal} / \mathrm{mol}$. $08-6$

Registry No.-1, 2025-95-8; 2, 569-41-5; 3, 50585-29-0; 4, 2026 -

\section{References and Notes}

(1) Supported by the National Science Foundation and the Public Health Service through Research Training Grant 5T01 GM-0126209-13CH to J. S. S.

(2) Centre D'Etudes Nucléaires de Grenoble, France.

(3) A very valuable review of the literature on this subject up to 1965 has been prepared by $V$. Balasubramaniyan, Chem. ReV, 66, 567 $\{1966\}$.

(4) Especially interesting $n m r$ studies relating to barriers to rotation and conformations of substances of this sort have been reported reconformations of substances of this sort have been reported re-
cently: (a) aryl-aryl interactions by $H$. O. House. W. J. Campbell, and M. Gall, J. Org. Chem., 35, $1815(1970)$, and H. O. House, D. G. Keopsell, and W. J. Campbell, ibid., 37, 1003 (1972); (b) alkylaryl interactions by D. L. Fields and T. H. Regan, J. Org. Chem., 36, 2986, 2991 (1971); see D. L. Fields, T. H. Regan, and R. E. Graves, ibid., 36, 2995 (1971); (c) alky/-alkyl interactions by J.E. Anderson, R. Franck, and W. Mandella, J.Amer. Chem, Soc. 94, 4608 (1972), and references cited therein.

(5) (a) See papers of the systematic investigations of A. I. Kitaigorodskll and Y. T. Struchkov, Zh. Strukt, Khim., 3, 184 (1962), and ref. erences cited therein; (b) G. Gofner and F. H. Herbstein, Nature (London), 200, 130 (1963), and earlier papers; (c) see also H. D. Rudolph, $H$. Driegler, $A$. Jarschbe, and $P$. Wendling, $Z$. Natur. 
forsch. A, 22, 940 (1967); O. Kennard and D. G. Watson, Mol. Struct. Dimensions, 1, 187 (1970).

(6) J. S. Sherfinski, Ph.D. Thesis, California Institute of Technology 1973.

(7) M. B. Jameson and B. R. Penfold, J. Chem. Soc., 528 (1965)

(8) D. M. Donaldson and J. M. Robertson, J. Chem. Soc., 17 (1953).

(9) Z. A. Akopyan and Y. T. Struchkov, Zh. Strukt. Khim., 5, 496 (1964); Z. A. Akopyan, A. I. Kitaigorodskii, and Y. T. Struchkov, ibid., 6, 729 (1965)

(10) J. R. Holden and C. Dickinson, Chem. Commun., 144 (1969).

(11) G. Evard, P. Piret, and M. Van Meerssche, Acta Crystallogr., 28, 497 (1972).

(12) D. E. Fenton, M. R. Truta, and B. L. Vickery, Chem. Commun., 93 (1971).

(13) H. Einspahr, J.-B. Robert, R. E. Marsh, and J. D. Roberts, Acta Crystallogr., Sec. B. 29, 1611 (1973).

(14) W. J. Mitchell, R. D. Topsom, and J. Vaughan, J. Chem. Soc. 2526 (1962).

(15) These cell dimensions agree well with the values reported by $Z$. A. Akopyan, R. L. Avoyan, and Y. T. Struchkov, Zh. Strukt. Khim., 4 $772(1963) ; a=23.56 \AA, b=7.67 \AA, c=12.54 \AA \AA A=95.5^{\circ}$

(16) All calculations were carried out on an IBM 370-155 computer under the CRYM system of crystallographic programs. The quantity minimized in the least-squares calculations was $\Sigma w\left(F_{0}{ }^{2}-F_{c^{2}}\right)^{2}$, with $w=\sigma^{-2}\left(F_{0}^{2}\right)$.

(17) W. H. Zachariasen, Acta Crystallogr., 16, 1139 (1963); A. C. Larson, ibid., 23, 664 (1967)

(18) D. W. J. Cruikshank, Acta Crystallogr., 10, 504 (1957)

(19) G. S. Pauley and E. A. Yeats, Acta Crystallogr., Sect. B, 25, 2009 (1969).

(20) L. Pauling, "Nature of the Chemical Bond," Brd ed, Cornell University Press, Ithaca, N. Y., 1960, pp 257-264.

(21) A. Bondi, J. Phys. Chem., 68, 441 (1964).

(22) (a) R. J. Abraham and Z. L. Rossetti, Tetrahedron Lett., 4965 (1972). (b) Similar results have been reported, but not explained in the same way, by R. D. Stolow, T. W. Giants, and J. D. Roberts, ibid., $5777(1968)$.

(23) S. Castellano and A. A. Bothner-By, J. Chem. Phys., 41, 3863 (1962).

(24) (a) R. W. Creceley and J. H. Goldstein, Org. Magn. Resonance, 2, 613 (1970); (b) M. W. Jarvis and A. G. Moritz, Aust. J. Chem., 24, 89 (1971); (c) P. M. E. Lewis, Tetrahedron Lett., 179 (1972)

(25) (a) L. M. Jackman and S. Sternhell, "International Series of Monographics in Organic Chemistry," 2nd ed., Pergamon Press, Elmsford, N. Y., 1969; (b) J. W. Emsley, S. R. Salman, and R. A. Storey, J. Chem. Soc. B, $1513(1970)$

\section{Notes}

\section{Kinetics of Hydrolysis of 0 -Tolunitrile in Moderately Concentrated Perchloric Acid Solutions ${ }^{1}$}

\section{J. F. Bunnett*2 and Fredric P. Olsen}

Metcalf Chemical Laboratories, Brown University, Providence, Rhode Island 02912

Received July 26, 1973

A kinetic study of the hydrolysis of benzonitrile was recently published by Hyland and O'Connor. ${ }^{3}$ This prompts us to report a set of data obtained some years ago ${ }^{4}$ concerning rates of hydrolysis of $o$-tolunitrile in $\mathrm{HClO}_{4}$ solutions at $133.5^{\circ}$.

The hydrolysis reaction is represented in eq 1 . An analytical technique was chosen that reveals only destruction of the nitrile and is insensitive to further hydrolysis of amide to acid. The data obtained in 1.5-6 $\mathrm{M} \mathrm{HClO}_{4}$ solutions are listed in Table I.<smiles>Cc1ccccc1C#N</smiles><smiles>Cc1ccccc1C(N)=O</smiles><smiles>Cc1ccccc1C(=O)O</smiles>

These data are correlated quite well by the linear free energy relationship (LFER) of eq 2 , in which $H_{0}$ is the Hammett acidity function, $k_{\psi}$ is the measured pseudofirst-order rate constant at any acid concentration, and $k_{2}{ }^{0}$ is the second-order rate constant (first order in substrate, first order in $\mathrm{H}^{+}$) at infinite dilution in water as reference state. ${ }^{5}$ The correlation and the resulting parameters are summarized in Table II. The slope ( $\phi$ value) is +0.61 .

$$
\log k_{\psi}+H_{0}=\phi\left(H_{0}+\log \left[\mathrm{H}^{+}\right]\right)+\log k_{2}{ }^{0}
$$

Correlation of $\log k_{\psi}+H_{0}$ with $\log a_{\mathrm{w}}{ }^{6}$ where $a_{\mathrm{w}}$ is the activity of water, was also attempted. That correlation is also summarized in Table II. The slope ( $w$ value) is +3.33. As revealed particularly by the standard deviations of points from the linear regression lines, $\sigma_{y}$, the correlation with $\log a_{\mathrm{w}}$ is less satisfactory than with $\left(H_{0}+\log \right.$ $\left.\left[\mathrm{H}^{+}\right]\right)$. A plot of the correlation with $\log a_{\mathrm{w}}$ shows slight but persistent curvature, whereas the LFER plot is
Table I

Kinetics of Hydrolysis of $a$-Tolunitrile in Aqueous Perchloric Acid at 133.5

\begin{tabular}{cccc}
\hline $\begin{array}{c}\left.\mathrm{HClO}_{4}\right], \\
M\end{array}$ & $\begin{array}{c}10^{5} k \psi_{,} \\
\sec ^{-1} a\end{array}$ & $H_{0}$ & $H_{0}+\log \left[\mathrm{H}^{+}\right]$ \\
\hline 1.47 & $2.12 \pm 0.06$ & -0.59 & -0.41 \\
3.01 & $6.42 \pm 0.43$ & -1.33 & -0.86 \\
4.00 & $12.5 \pm 0.55$ & -1.79 & -1.18 \\
4.51 & $16.0 \pm 0.35$ & -2.02 & -1.38 \\
4.99 & $19.8 \pm 0.53$ & -2.28 & -1.58 \\
5.50 & $32.0^{5}$ & -2.59 & -1.85 \\
6.02 & $38.3 \pm 1.15$ & -2.90 & -2.12
\end{tabular}

a Standard deviations are shown. ${ }^{b}$ Average of $31.7 \pm$ 0.7 and $32.3 \pm 1.4$.

Table II

Summary of Rate Correlations

\begin{tabular}{cccccc}
\hline Correlation & Slope & Intercept & $\sigma_{y}{ }^{a}$ & $\sigma_{\mathrm{Bl}}{ }^{b}$ & $r^{c}$ \\
\hline$\left(\log k_{\psi}+H_{0}\right)$ vs. & & & & & \\
$\left(H_{0}+\log [\mathrm{H}+]\right)$ & $+0.61^{d}$ & -4.99 & 0.03 & 0.02 & 0.997 \\
$\left(\log k_{\psi}+H_{0}\right) v s$. & & & & & \\
$\log a_{\mathrm{w}}$ & $+3.33^{e}$ & $f$ & 0.04 & 0.16 & 0.994 \\
$\log k_{\psi} v s .-H_{0}$ & +0.55 & $f$ & 0.05 & 0.03 & 0.994
\end{tabular}

a Standard deviation of points, in the $y$ direction, from the linear regression line. ${ }^{b}$ Standard deviation of slope. - Correlation coefficient. ${ }^{d} \phi$ value. ${ }^{\circ} w$ value. ${ }^{f}$ Not listed; has no fundamental significance.

straight except for small random deviations most likely due to experimental error.

Correlation of $\log k_{\psi}$ with $-H_{0}{ }^{7}$ was also attempted, and the correlation is summarized in Table II. The $\sigma_{y}$ values show that this correlation gives the least satisfactory fit of experimental points to a straight line. The slope is 0.55 .

The $H_{0}$ values $^{8}$ and $\log a_{\mathrm{w}}$ values $^{6}$ employed in these correlations are for $25^{\circ}$ or thereabouts, while the reactions were conducted at $133.5^{\circ}$. Also, acid concentrations were not corrected for thermal expansion of the reaction solutions from room to reaction temperature. The magnitudes of the slopes and intercepts may therefore be somewhat affected. The $\phi$ parameters measured by Hyland and 